\title{
Exposing the Conscious Self: Lived Problem Solving Experience in a Socio-Cultural Context
}

\author{
Iman C. Chahine ${ }^{1^{*}}$ \\ ${ }^{1}$ University of Massachusetts Lowell, USA

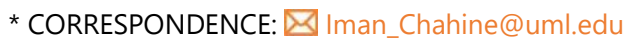

\begin{abstract}
My charge in this study is to explore the lived experience of a high school teacher while immersed in a problem solving situation in a classroom setting. The main gist of this investigation is to textualize and, thereof, capture the essence of a teacher's encounter of failing to solve a mathematics problem during one of the classroom sessions. To this end, I use personal experience as a lens to reflect on a teacher's reconstruction of the situation where personal meanings about problem solving and the problem-solving instruction are concealed.
\end{abstract}

Keywords: problem solving, mathematics teaching, lived experience, socio-cultural context

\section{INTRODUCTION}

A growing body of research on mathematics teachers' knowledge, beliefs, practices, and professional development are framing our conceptualization of what it means to become a mathematics teacher (Brown \& McNamara, 2011; Chahine \& King, 2012; Hill et al., 2004; Leatham, 2006). The impetus of such a corpus of studies is to gain an in-depth understanding of the dynamic and complex processes that characterize the daily practice of teaching in the mathematics classroom. Lester (1994) draws attention to the ongoing underrepresentation of research that specifically explores the affective and emotional predispositions of teachers while predominantly engaged in teaching through problem solving. In particular, Lester points out that very little of the literature on mathematical problem-solving instruction discusses the specifics of the teacher's role or the teacher's perspective of that role. Gläser-Zikuda, Stuchlikova, and Janik (2013) argue that the emotional aspect of teaching and learning is often overlooked when exploring issues related to student achievement in the classroom. Equally under-represented in the literature are studies on how teachers frame their identity in the context of teaching. Interestingly, this vacuum in research input is inconsistent with the prominent role that problem solving plays in the current reform movement in mathematics education (National Governors Association Center, 2010).

Globally, current reform recommendations in mathematics education emphasize a problem solving perspective to teaching mathematics as the principal instructional technique to enhance students' explorations of vital mathematical content (O'shea \& Leavy, 2013). This perspective necessitates that teachers understand "authentic" problem solving before guiding their students through the process. However, given the differential training during initial teaching preparation programs, teachers might not have opportunities to adequately experience robust mathematical problem solving as a disciplined way of thinking and reasoning, which as a result makes them less confident to adopt in their teaching.

Another factor to consider is the relationship between teacher beliefs about mathematics and their perspectives on teaching mathematics. There is ample evidence in the literature that supports the claim that beliefs about mathematics and its teaching play a significant role in shaping teacher behavior in the classroom

\footnotetext{
Article History: Received 5 June $2018 \bullet$ Revised 22 August $2018 \bullet$ Accepted 28 August 2018

(C) 2018 The Author(s). Open Access terms of the Creative Commons Attribution 4.0 International License (http://creativecommons.org/licenses/by/4.0/) apply. The license permits unrestricted use, distribution, and reproduction in any medium, on the condition that users give exact credit to the original author(s) and the source, provide a link to the Creative Commons license, and indicate if they made any changes.
} 
(Looney, Perry \& Steck, 2017; Sanger \& Osguthorpe, 2011; Torrey, 2017). By the same token, it has been argued that significant and meaningful teaching reforms are unlikely to take place unless teachers are willing to engage in metacognitive self-dialogue continuously challenging beliefs they deeply hold regarding best practices for teaching mathematics. Implicit in this relationship between teachers' beliefs and practices is a focus on self-understanding vis á vis teachers' thinking and behaviors. Specifically, in teacher-centered educational settings where instruction is predominantly teacher led and where a teacher embodies the main source of information, there is a heightened emphasis on teacher competence in content and pedagogy to facilitate student acquisition of related concepts. As a result, teacher effectiveness is constantly scrutinized and inspected in correlation with student's academic success. Goddard, Hoy and Woolfolk-Hoy (2004) contend that teachers' positive perceptions of their self-efficacy remarkably drive their willingness to enact change in their teaching practices. Needless to say that teacher performance has been inextricably linked to student achievement (Hanushek, \& Rivkin, 2012; Rockoff, \& Speroni, 2010; Wenglinsky, 2000), I argue that surveying teachers' challenges and opportunities as well as examining the impact of curricular support efforts on their perceived self-efficacy could help inform and thereby direct the design of rigorous professional development initiatives focused on building sustainable cadre of proficient teachers responsive to students' growth toward improved academic outcomes.

My charge in this study is to explore the lived experience of a high school teacher while immersed in a problem solving situation in a classroom setting. The main gist of this investigation is to textualize and, thereof, capture the essence of a teacher's encounter of failing to solve a mathematics problem during one of the classroom sessions. To this end, I use personal experience as a lens to reflect on a teacher's reconstruction of the situation where personal meanings about problem solving and the problem-solving instruction are concealed.

To unpack the lived experience from a socio-cultural perspective, I envision the teacher's classroom behavior on a past-future spectrum. In relation to this past-future structure, Carr (1986) describes three critical dimensions of human experience: significance, value, and intentions. In Carr's terms, the past conveys significance, the present conveys value, and the future conveys intentions. I argue that as teachers focus and reflect on their lived experiences, they are more likely to conceptualize their teaching practices in terms of personal meanings they attach to past, present, and future encounters and which, in turn, shape the behavior they display in the classrooms. I postulate that teachers tend to conceptualize their teaching behavior within frames of personal meanings and epistemologies that emerge in the context of their teaching practice. According to Hammer and Elby (2002), personal meaning is constructed from experience and reflects an amalgam of the individual and the social. By the same token, Polani (1958) contends that personal meaning is also a basis for organizing one's knowledge and behavior and acts as a catalyst to forging one's identity relative to their daily teaching practice. In this sense, I argue that a teacher's personal epistemology embodies what the teacher feels, thinks, believes, and wants. Personal epistemologies, then, can be employed as a basis for examining and modifying the ways in which teachers perceive, make meaning of, and execute their professional tasks. To expose the essence of this meaning, it is necessary to engage in an internal reflective dialogue that grazes deep beneath the surface. My tacit assumption in this study is that teachers' personal epistemologies can be probed and exposed as teachers immerse themselves in a state of "mental flow" where they consciously and purposely reflect on past experiences and dispositions.

\section{PERSONAL EPISTEMOLOGY FRAMEWORK}

I adopt Hofer and Pintrich's (1997) interrelated dimensions model as the primary theoretical and methodological framework that guide the interpretation of the phenomenon under investigation (See Figure 1). Pintrich (2002) defines the construct of personal epistemology as comprising beliefs about the nature of knowing as it relates to the certainty and simplicity of knowledge on one hand and to beliefs regarding the nature of knowing with particular emphasis on the sources of knowledge and the justification for knowing on the other hand. 


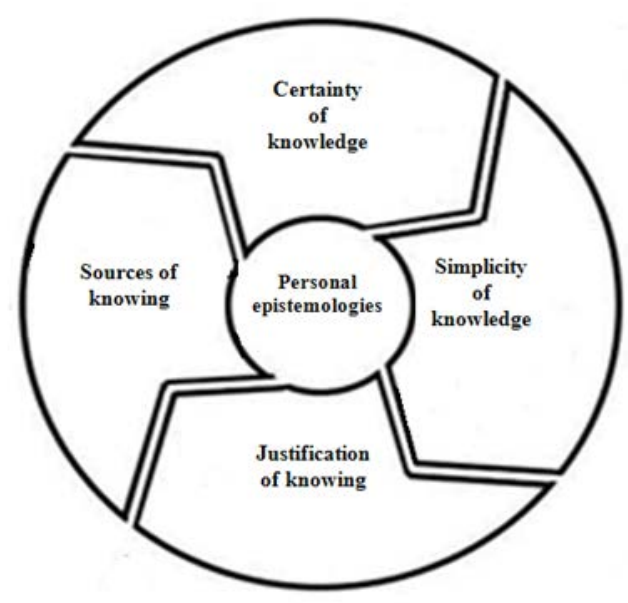

Figure 1. Author's depiction of Hofer \& Pintrich's dimensions of personal epistemology

In a similar vein, Baxter-Magolda (2004) epitomizes the role of four core beliefs in depicting personal epistemology but goes further to emphasize how the "self", learning, and social context are inextricably linked to epistemological beliefs. Particularly in the teaching practice, there is strong evidence supporting the claim that beliefs teachers hold about the nature of knowledge and knowing could directly impact the way teachers deliver the instruction, particularly in mathematics classrooms (Muis, 2008). Furthermore, Hoffer (2002) argues that personal epistemologies are stimulated during the process of teaching thereby influencing teachers' abilities to engage meaningfully in complex problem solving. In this respect, Schulte (2013) confirms that unless teachers hold "sophisticated" personal epistemologies (i.e., beliefs that knowledge is uncertain and integrated), they are less likely to be able to effectively maneuver and respond to challenges that incur in their daily teaching practice and to be open to multiple perspectives and ways of thinking. Additionally, Schraw and Sinatra (2004) explain that teachers adopting sophisticated personal epistemologies adapt their teaching strategies to the classroom climate and engage more with their students.

The bulk of literature on personal epistemologies and teaching practice shows clear links among teachers' level of personal epistemology (i.e., sophisticated vs. naïve), their approaches to knowledge, and their teaching beliefs. Studies on preservice teachers' personal epistemologies arguably revealed that teachers in their early years of teaching usually hold "naïve" beliefs about the nature of knowledge and knowing where they view knowledge as "received absolute truths (e.g., individuals passively receive truths from authority that are a direct copy of reality" (Yadav, Herron, \& Samarapungavan, 2011, p.79). I argue that engaging teachers in discourses where they explicitly reflect on their personal epistemologies could help them understand their conceived beliefs and thus be able to regulate and calibrate these epistemologies to various teaching situations.

\section{THE STUDY CONTEXT}

The study was conducted during a 10-day trip the author took to Kwa Zulu Natal province in South Africa. The purpose of the trip was to visit schools and meet with teachers to explore the daily practice of teaching mathematics in light of the post-apartheid curriculum reform set in place by the Department of Education in 2005.Under apartheid, the South African education system supported disproportionate distribution and access to quality resources in schools, which resulted in many educational challenges. Since the establishment of a new post-apartheid political regime, a new governance system emerged that called for comprehensive reform in curricula by developing outcome-based education (OBE) and establishing school governing bodies (SGBs) encouraging community participation in schooling policies (Cross, Mungadi, \& Rouhani, 2002). However, and contrary to all expectations, post-apartheid education reform efforts faced numerous tensions and constraints as a result of existing realities and dysfunctional practices. These tensions were mainly due to clashes between the ideal vision that the new curriculum project is advocating and what schools can realistically achieve.

Like many countries with centralized educational systems, most decisions related to educational policies in South Africa are strictly managed by the Ministry of Education (MoE). Despite the establishment of School Governing Bodies (SGB) by the MoE, the provincial Member of the Executive Council (MEC) for Education 
determines election procedures within the framework created by the South African Schools Act (SASA). The SGB stands in a position of trust towards the schools (Chahine, Kinuthia \& Maxwell, 2013). Throughout the Kwa Zulu Natal province, MoE has developed and enacted policies in the education sector directed toward the grass root level. However, all matters pertaining to curriculum are still centrally controlled by MoE and its agencies. Predictably, this reality continues to reinforce the deep inequalities still prevalent in the educational system and reflects one of the shortcomings of the post-apartheid curriculum reform, namely discouraging critical engagement in policy debates (Alexander \& November, 2010). In such a scenario, it is highly expected that teachers feel left out; their voices seldom heard since their participation in the decision process is superficial. In all likelihood, a climate of tension combined with heavy teaching loads, large classes, a tight daily schedule and rules that discourage mutual interactions among colleagues have made teachers' work more isolated and ultimately isolating (Huffman \& Kalnin as cited in Chahine \& King, 2012). According to a report released by the Center for Development and Enterprise (CDE) in 2011, mathematics and science teachers are generally uninterested and underpaid, only two-thirds spend $46 \%$ of their time actively teaching and over $25 \%$ of newly qualified teachers pursue other professions when given a more profitable job opportunity. Similarly, Claypool and Bernstein (2014) argue that poor societal perceptions of teaching and the lack of serious efforts to develop support systems that cultivate highly-effective teachers have presented unprecedented challenges for teachers to deliver quality instruction particularly in vital subjects such has mathematics.

In light of the prevalent educational climate, the following questions are prompted: What happens when teachers implement a mandatory mathematics curriculum distinctly different from what they taught in the past? And how do teachers' understandings and personal beliefs about their teaching practice unfold as they engage in implementing reform? Specifically, this study examines this question: What is the nature a problem solving experience that afforded an insight into a mathematics teacher's personal epistemology?

\section{METHODOLOGY}

I adopt a phenomenological methodology as a systematic attempt to depict a teacher's reconstruction of a lived experience by potentially uncovering and describing the conscious meaning structures that surface as the teacher narrates her encounter (van Manen, 2003). Creswell (2007) reminds us that a phenomenological approach seeks to understand and describe the meaning of a phenomenon that is experienced by several individuals and deals with human issues, including human occupation. In this way, the essence of the human experience is explored beyond the reductionist perspective, thereby bringing value to the study of human activity (Creswell, 2007; Sadala \& Adorno, 2002). I argue that to do phenomenology is to construct a full interpretive description of some aspect of the phenomenon, and to remain aware that lived experience is always more complex than any explication of meaning. van Manen (2003) explains that a good description that constitutes the essence of something is interpreted so that the structure of a lived experience is revealed to permit full grasp of this experience.

As originator of phenomenology, Husserl methodology was to begin with the "phenomenological reduction" or "epoche" which involved the attempt to put all of one's assumptions about the matter being studied into halt, to "bracket" them. As Giorgi (1997) pointed out, to proceed without this step when reflecting upon personal experience leaves one open to the "psychological fallacy", namely, the likelihood that one's judgments about such experiences will be biased by various preconceptions, wishes, desires, motives, values and other influences.

\section{Data Collection}

To explore the teacher's perceptions of a problem solving situation, I employ a phenomenological approach centered on personal interpretations of lived experiences captured and extracted from interviews (De Gagne $\&$ Walters, 2010). The data source for this study is a single actual life-text description of the experience of one participant. The author conducted face-to-face interviews with the participant, particularly focusing on providing a temporal space where fine-grained descriptions of the lived experience facilitated the discovery of meaning and essence of the problem solving phenomenon under consideration. The interviews were audio recorded, transcribed, and reflectively and interpretively articulated in terms of inherent hidden meanings. I used fine-grained analysis of the transcribed notes from the interviews to identify recurring themes that depict how the participant perceived her knowledge of mathematics in the context of the problem solving episode. Based on the four aforementioned dimensions of Hofer and Pintrich's (1997) framework of personal epistemologies, I employ a deductive approach to categorize the teacher's reflections. Categorizations related 


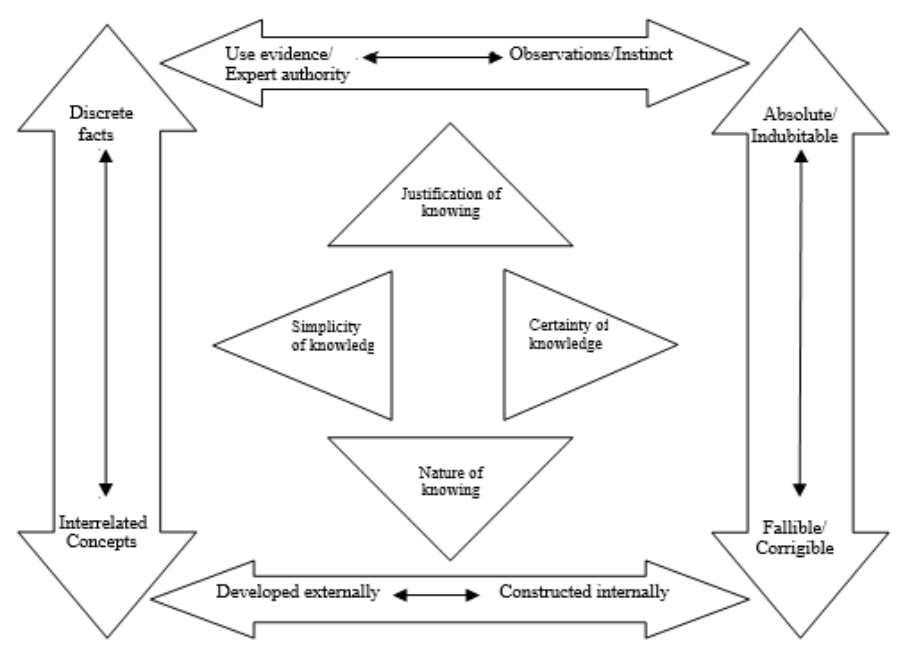

Figure 2. Author's depiction of dimensions of personal epistemology

to participant's perception of the nature of knowledge included: certainty of knowledge and simplicity of knowledge. On the other hand, classifications related to the nature of knowing included participant's belief vis à vis justification of knowing and sources of knowing (See Figure 1). Hofer (2002) explains that perceptions related to the certainty of knowledge range from beliefs in knowledge as absolute, indubitable truth to the belief that knowledge can be fallible and corrigible. With regards to the levels of knowledge simplicity, Schommer (1994) argues that knowledge may be viewed on a continuum of accumulated discrete facts on one hand to a set of highly interrelated concepts on the other. When exploring beliefs related to the nature of knowing, Baxter-Magolda (1992) highlights a trajectory that depicts the perception of knowing as originating externally, outside the self to being internally constructed by individuals as they actively and purposively interact with the outside world. Furthermore, King and Kitchener (1994) contend that to justify what they know, some individuals tend to use observation or instinctive feelings while others use evidence relegated from expert authority (See Figure 2).

\section{The Participant}

The author met the participant during an informal visit to a high school in Durban in the Kwa Zulu Natal province in South Africa. After meeting with the teachers at the school and engaging in informal conversations related to their daily teaching practice, a young mathematics teacher was willing to share a lived experience she encountered in teaching mathematics early in her teaching career and volunteered to be the participant for the study. The participant is a female with more than twelve years of teaching experience in several public schools. Prior to conducting the study, ethics approval for the research, was granted from the Research Ethics Board where the participant was assured of anonymity in every aspect of the research study including written reports and audiotaped records.

\section{Interviews}

The study was conducted over a period of 10 days during which the author conducted four interviews with the participant. The interviews were guided by using open-ended questions that enabled the participant to provide vivid, fine-grained description of her experience as recollected from memory. While conducting the interviews, I adopted the following stance: 1) Concentrating on the described situation, 2) Slowing down and patiently dwelling with the participant on the details of the description, 3) Magnifying the details, 4) Turning from objects to meanings, 5) Being open, suspending belief and employing intense interest.

\section{Protocol Analysis}

Analysis was initiated by uncovering essential themes which were either stated explicitly by the participant's words or hinted at implicitly by the overall structure of the narrative. Because of the richness of the data, I was cautious not to lose the essence of the experience during the process of interpretation as I moved from the raw data successively toward the essential constituents. Multiple readings of the transcribed 
narrative afforded the emergence of evidence related to dimensionality in personal epistemology and the linkages between beliefs and practice. It was essential to further clarify and articulate any interpretation of meaning that is influenced by my subjectivity and pre-understandings as a mathematics teacher. Furthermore, I employed Lichtman's (2006) 3Cs for textual data analysis: Coding fragments of ideas, Clustering relevant ideas, and Categorizing by abstracting concepts and themes.

Protocol analysis was conducted in several stages. After multiple readings of the transcribed narrative, I identified significant statements directly pertaining to the experience that was categorized under Hofer and Pintrich's (1997) four interrelated dimensions of personal epistemology: simplicity of knowledge, certainty of knowledge, sources of knowing, and justification of knowing. The protocol was analyzed to discern natural breaks in the meaning pertinent to the experience as a whole. According to Giorgi (1997), meaning units are perceived as transitions related to the sensitivity of the researcher. The significant statements were sorted into theme clusters, which were further condensed to form constituent themes. The protocol is reread several times with the categories in mind to check for the comprehensiveness of the themes. The essence of the phenomenon was then derived from the final comprehensive constituent themes.

In extracting the themes, the main foci included shedding light on the meaning of the phenomenon as experienced by the participant and examining how events are integrated to form a dynamic meaningful experience. To reflect on the verbatim transcribed notes, I tried to extrapolate inherent meanings beyond the textual data in order to conceptualize insights extracted from the experience. By focusing on the essential constituents specifically indicative of the participant personal epistemology, I tried to capture essential nuances by aligning valid and plausible descriptions that maintained the integrity, complexity and essential being of the experience as depicted by the participant.

\section{RESULTS}

\section{Perception of Problems and Problem Solving}

The participant construed a mathematics problem as any situation that had barriers to a solution. Such situations could occur in a variety of forms. Consistent with this view of problems, the teacher's thinking of problem solving reflected a more flexible process. The teacher viewed mathematical problem solving as an open-ended process in which the problem solver had to be in control in terms of interpreting the problem and deciding on how to overcome barriers to a solution. The process could be unpredictable in terms of what might or might not work. Thus, problem solving was viewed as involving a cycle of failure and success. Both positive and negative emotions were natural consequences of the process. In particular, it has to do with thinking and knowing what to do to get out of being stuck. In the course of narrating her experience, it was clear that the teacher embraced a more realistic view of problem solving that exposed past nuances of emotions and frustrations she encountered as integral features of the problem solving act and not as situations she created because something went wrong.

\section{Constituent Themes}

The epistemological framing of the structure of the phenomenon arouse from pondering and reflecting on my own classroom experiences as a mathematics teacher, the choices I have made as well as the conversation I had with the participant. Questioning the meaning of the lived experience led to the widening of the "horizon" of what it meant to be immersed in a particular problem solving experience. By means of "explication" I come to discover what the essential constituents of the phenomenon under study. van Kaam (1966) defined explication as making explicit the implicit awareness of a complex phenomenon. Through "explication", I tried to screen out those "imaginative variations" to reach an understanding of what the phenomenon essentially embodies. By selecting, focusing, simplifying, and transforming, I extracted ten constituent themes that emerged as I examined the participant's narrative account. These identified themes encompass every meaning statement I found significant in protocol analysis and illustrated a South African teacher recollection of a lived problem solving experience. Principled by the theory of personal epistemologies, I clustered the themes under Hofer and Pintrich's (1997) four epistemological beliefs: certainty of knowledge; simplicity of knowledge; sources of knowing and justification of knowing.

\section{Simplicity of Knowledge: Being in Control}

A wide range of mathematics education research on problem solving has advanced the thesis that the tangible cognitive actions involved in solving a mathematics problem are often the result of consciously or 
unconsciously held beliefs about the task at hand, the social environment within which the tasks take place, and the individual problem solver's perception of self and his or her relation to the task and the environment. In his seminal work, Schoenfeld (1983) proposed that in addition to seeking cognitive explanations of problem solving behavior, other factors need to be considered. Specifically, he suggested that any problem solving situation should be analyzed with respect to three qualitatively different categories of knowledge and behavior: resources (or knowledge base), control, and belief systems. The bulk of research on problem solving has focused on how one has control of how to store and retrieve information. Losing control, physically and mentally, seemed to be an essential instance of the lived experience. In her words, the teacher explained:

I felt the unassailable truth...I am the worst teacher...the lesson is flopping and everything is out of control...

Also, when she said:

After a while... with a feeble...so low-pitched voice, I moved onto something I have prepared and which I am most comfortable with-Something I have control on- I wasn't in control... that was the main thing...

There is a great value attached to being in control, losing this sense is a sign of failure, of weakness and disintegration. Schommer-Aikins (2002) argued that teachers who hold the view that knowledge is simple believe that learning is equivalent to accumulating a vast amount of factual knowledge that is passed on from a reliable source that has control and ownership of the knowledge capital. Being the locus of control was essential for the teacher as she believed the degree of control that teacher has in the classroom determines how and what students learn. This belief is commensurate with the view that learning can only occur as a direct outcome of teaching, and that knowledge in the classroom can only be delivered by the teacher. Losing control and not being prepared intellectually and emotionally are perhaps among many instances that put teachers under stress.

\title{
Simplicity of Knowledge: Continual Questioning
}

\section{And a raging stream of thoughts kept flowing in my mind....how can I face the students after this disappointment?}

There is considerable agreement that people are moved to learn when they ask themselves questions. This provoking of learning is perhaps a major necessity for teachers to question their performance and reflect on their practices as problem solvers. Through continual questioning, the teacher tried to make visible an awareness of lacks and deficiencies and to highlight the dark times, the fears, and the felt failures. Feeling the need to physically and mentally escape the experiential space:

Blocking everything out... not wanting anybody else to be with me-trying to ignore the whole thing just looking at it very quickly not wanting any one to engage me... not looking at them...wishing I can just evaporate...get away from their sight... remove from myself and from everybody else.

Throughout the lived text, there was a wide range of intense, at times overwhelming, emotions, anger, guilt, helplessness, and panic. During these times, there was often a need to escape, to get out, a feeling of not being able to stay a minute there. At times, there was not just the desire to leave physically but a sense of distancing oneself from the surrounding.

\section{Simplicity of Knowledge: Inability to Act}

\author{
...I felt I am going to fall down...something kept pulling down as if wanting to sit, I felt my body \\ slipping...pushed... I felt a bit faint
}

Many studies have highlighted the immediacy of much that occurs in the activity of teaching in general and teaching mathematics in particular (LeFebvre \& Allen, 2014). Such immediacy makes it very difficult for teachers to weigh in a detached fashion each and every word or act in the classroom. Teacher "immediacy" or as Garrison (2007) defines "teacher presence" is a necessary prerequisite for teaching effectiveness and students' attentiveness. By the same token, Garrison and Anderson (2003) propose a 3-tier conceptualization of teacher presence: a) social presence; b) cognitive presence; and c) teaching presence. The inability to act 
seemed to be one restraining moment that the mathematics teacher lived when not being able to solve a problem posed by a student.

\title{
Simplicity of Knowledge: Awakening of the Self to the Other
}

That made me think about how we, as teachers, should accept the idea that we are vulnerable and be sensitive to how we evaluate our students...

The encounter may manifest itself as a sense of lack, of deficiency, or of something suddenly seen as in need of repair. This moment of sudden almost unwilling awakening has been and still is being dramatized particularly in the context of teaching mathematics where the idea of infallibility dominates. From a positivist's perspective, mathematical knowledge is characterized as being infallible (Ernest, 1998), hence teachers are expected to consciously exhibit this certainty in the way they communicate ideas to their students. Even as many of us as mathematics teachers cling to the familiar or to forms that seem to confirm to what we already know, we are, on the same level, rejecting stagnation and "objectness." The participant came to the realization that perhaps part of teaching is to come in contact with that sense of incompleteness and to detach from the perception of certainty and infallibility.

\section{Simplicity of Knowledge: Developing Ways of Coping with Things one can't Change}

\author{
I wasted a lot of time-in denial-trying to talk about it... trying to pretend that it is a learning experience \\ for them...unconsciously lecturing that it is not just knowing the answer that matters... and \\ eventually... said it is not working out.
}

In mathematical problem solving, Schoenfeld (1983) highlighted two fundamental dimensions of good practice namely, the control over the process of working on problems, and a deep understanding of the nature of mathematical argumentation. Losing control, the participant tried to argue her way out from a seemingly dissonant situation, to defend her position and free herself from chains of embarrassment or sufferings.

\section{Simplicity of Knowledge: Experiencing an Altered, Unreal Reality}

\author{
The things that I used to imagine are not actually true. I had blown the situation in my mind and \\ exaggerated... it is not really true.
}

The common notion of expertise in teaching among in-service teachers' spotlights what teachers know with respect to a particular domain of knowledge and application. In the early years of teaching, mathematics teachers are held accountable in the extent to which they are competent in mathematics. As mathematics teachers, we are always expected to fully provide accurate answers to every question posed. While we extensively emphasize comprehensive knowledge of mathematics as a subject matter in our teacher preparation program, we are rarely exposed to notions of moral knowledge. The idea of moral knowledge points neither to a specific body of facts and theories nor to a predefined content of any kind. Rather, it signifies an appreciation of how difficult it is to know something well, of how little in fact, we know, and of how much we will always want and need to know.

\section{Certainty of Knowledge: Teacher as the Sole Authority- Knows Everything}

I felt I should know everything because I was the teacher so I should not do mistakes...

The resilience of the common patterns of mathematics instruction reflects what has been called the "mimetic" tradition, which is at odds with the more ambitious instruction that is advocated by reformers. Knowledge is seen as fixed; teachers give knowledge to students who store and remember it (Cohen, 1989). The view that knowledge is fixed, that teaching is achieved through transmission, and that teachers are authorities run deeply in the participant's consciousness of the teaching and learning of mathematics. It is quite obvious the pressure that the teacher feels to make sure that all students master the required content. The common maxim that has long been prevailed in schools is that the more mathematical knowledge teachers have, the more mathematical knowledge their students will have. Being the source of knowledge dissemination, it has been of utmost importance for the teacher to provide a proper answer to the question posed by the student. 


\title{
Certainty of Knowledge: Not being able to Live up to Others Expectations
}

\author{
I should understand everything and that's what I think they expect. What we say and do as teachers, \\ matters...It matters a lot.
}

Scheffler (1968) argues that the practice of teaching involves a "restriction of manner" on how teachers can conduct themselves. Needless to say, these self-expectations place a burden on the teachers to be at their best when in the presence of students. Such self-expectations may lead teachers into moral dilemmas if not into actual conflicts with themselves and with their students. Such a view contradicts the current interest in teaching with problem-solving as a "practice" that reflects a trend in which learners are characterized as more active and where problem-solving is viewed as a process of negotiations of ideas. When training as teachers, we become aware of the many demands that we will face upon entering the chosen profession. Apart from meeting the academic and professional requirements of teaching, teachers try to find their own voice and personal aspirations. Yet, teachers are aware that in so many ways they are acting on behalf of others and their own particular priorities. Arguably, our sense of self is fashioned by the expectations of others.

\section{IMPLICATIONS}

To summarize, the paper is primarily concerned with examining how a teacher conceptualized her problem solving experience. To this end, I raise a number of theoretical and empirical aspects in relation to teachers' epistemological beliefs. First, I present an account of how a mathematics teacher understood and conceptualized her practice in a problem solving situation. Second, I examine the personal conceptions of knowledge as it emerged from the teacher's narrative in light of the social parameters that guide these conceptions. Yet conceptions of teacher personal epistemologies fix understandings of mathematical knowledge and its teaching in schools. Many countries have experienced major curriculum reform in recent years. In a South African context, the regulation of teaching in schools and racial changes to teacher training have been significant. This paper was a modest attempt to examine the limits of centralized control and how this is processed through the actions of teachers. The themes emerged from the study are germane to understanding the lived experience of a teacher in a problem solving situation. Its implications are personal and allude to revising common conceptions concerning teachers' pedagogical content knowledge. From a phenomenologist view of lived experience, the notions of teaching mathematics are much involved with notions of human relations, inter-subjectivity, and the pursuit of various kinds of meanings. As mathematics teachers, we feel a great drive to focus on communicating certain procedures, methods, and processes to enable students to learn effectively and meaningfully.

Ultimately in schools, understandings of mathematics emerge in the interplay between teachers and the societal structures they inhabit. These understandings derive from a variety of culturally based assumptions as to the nature of mathematics and the associated norms of accountability they produce. The diverse criteria that apply in setting educational priorities can result in teachers being pulled in many directions. In a social environment of great complexity, teachers are driven to exhibit much personal restraint. This paper aimed at creating a better understanding of how teachers might be equipped to assert their own voices.

\section{Disclosure statement}

No potential conflict of interest was reported by the authors.

\section{Notes on contributors}

Iman C. Chahine - University of Massachusetts Lowell, USA.

\section{REFERENCES}

Alexander, G., \& November, I. (2010). Outcomes in South African Higher education: Imagine that! Journal of Social Science, 24(2), 101-109. https://doi.org/10.1080/09718923.2010.11892841

Baxter Magolda, M. B. (1992) Knowing and reasoning in college: Gender related patterns in students' intellectual development. San Francisco, CA: Jossey-Bass.

Baxter-Magolda, M. (2004). Evolution of a Constructivist conceptualization of epistemological reflection. Educational Psychologist, 39(1), 31-42. https://doi.org/10.1207/s15326985ep3901_4 
Brown, T., \& McNamara, O. (2011). Becoming a mathematics teacher. Dordrecht, Netherlands: Springer. https://doi.org/10.1007/978-94-007-0554-8

Brownlee, J., Schraw, G., \& Berthelsen, D. (2011). Personal epistemology and teacher education: An emerging field of research. In J. Brownlee, G. Schraw, \& D. Berthelsen (Eds.) Personal epistemology and teacher education (pp. 3-24). New York, NY: Routledge.

Carr, D. (1986). Narrative and the real world: An argument for continuity. History and Theory, 25(2), 117-131. https://doi.org/10.2307/2505301

Chahine, I. C., \& King, H. (2012). Investigating Lebanese teachers' mathematical, pedagogical and self-efficacy profiles: A case study. Near and Middle Eastern Journal of Research in Education. https://doi.org/10.5339/nmejre.2012.2

Chahine, I.C., Kinuthia, W., \& Maxwell, K. (2013). Surveying technologies for integrating indigenous knowledge systems in the mathematics classrooms in Durban-South Africa: Potentials and challenges. Indilinga: African Journal of Indigenous Knowledge Systems, 12(1), 37-51.

Claypool, H. M., \& Bernstein, M. J. (2014). Social exclusion and stereotyping: Why and when exclusion fosters individuation of others. Journal of personality and Social Psychology, 106, 571-589. https://doi.org/10.1037/a0035621

Cohen. D. K. (1989). Teaching practice. In P.W. Jackson(Ed.). Contributing to educational change: Perspectives on research and Practice (pp.27-84). Berkeley, CA: McCutchan.

Creswell, J. W. (2007). Qualitative inquiry and research design: Choosing among five approaches ( $2^{\text {nd }} \mathrm{ed}$.). Thousand Oaks: CA. Sage.

Cross, M., Mungadi, R., \& Rouhani, S. (2002). From policy to practice: Curriculum reform in South African education. Comparative Education, 38(2), 171-187. https://doi.org/10.1080/03050060220140566

De Gagne, J. C., \& Walters, K. J. (2010). The lived experience of online educators: Hermeneutic phenomenology. Journal of Online Learning and Teaching, 6(2), 357-366.

Garrison, D. (2007). Online community of inquiry review: Social, cognitive, and teaching presence issues. Journal of Asynchronous Learning Networks, 11(1), 61-72.

Giorgi, A. (1997). The theory, practice and evaluation of the phenomenological method as qualitative research procedure. Journal of Phenomenological Psychology, 28(2), 235-260. https://doi.org/10.1163/156916297X00103

Glaser-Zikuda, M., Stuchlikova, I., \& Janik, T. (2013). Emotional aspects of learning and teaching: Reviewing the field discussing the issues. Orbis Scholae, 7(2), 7-22. https://doi.org/10.14712/23363177.2015.18

Goddard, R. G., Hoy, W. K., \& Woolfolk Hoy, A. (2004). Collective efficacy: Theoretical development, empirical evidence, and future directions. Educational Researcher, 33, 2-13. https://doi.org/10.3102/0013189X033003003

Hammer, D., \& Elby, A. (2002). On the form of a personal epistemology. In B. K. Hofer and P. R. Pintrich, (Eds.), Personal Epistemology: The Psychology of Beliefs about Knowledge and Knowing (pp 169-190). Mahwah, NJ: Erlbaum.

Hanushek, E. A., \& Rivkin, S. G. (2012). The distribution of teacher quality and implications for policy. Retrieved from http://hanushek.stanford.edu/sites/default/files/publications/Hanushek\%2BRivkin\%20 2012\%20AnnRevEcon\%204.pdf https://doi.org/10.1146/annurev-economics-080511-111001

Hill, H. C., Ball, D. L., \& Schilling, S. G. (2004). Developing measures of teachers' mathematics knowledge for teaching. Elementary School Journal, 105(1), 11-30. https://doi.org/10.1086/428763

Hofer, B. K. (2002). Personal epistemology as a psychological and educational construct: An introduction. In B. K. Hofer \& P. R. Pintrich (Eds.), Personal epistemology: The psychology of beliefs about knowledge and knowing (pp. 3-14). Mahwah, NJ: Lawrence Erlbaum Associates, Inc.

Hofer, B. K., \& Pintrich, P. R. (1998). The development of epistemological theories: Beliefs about knowledge and knowing and their relation to learning. Review of Educational Research, 67(1), 88-140. https://doi.org/10.3102/00346543067001088

Leatham, R. (2006). Viewing mathematics teachers' beliefs as sensible systems. Journal of Mathematics Teacher Education, 9(1), 91-102. https://doi.org/10.1007/s10857-006-9006-8

LeFebvre, L., \& Allen, M. (2014). Teacher immediacy and student learning: An examination of lecture/laboratory and self-contained course sections. Journal of the Scholarship of Teaching and Learning, 14(2), 29 - 45. https://doi.org/10.14434/josotl.v14i2.4002 
Lester, F. K. (1994). Musings about mathematical problem-solving research: 1970-1974.Journal for Research in Mathematics Education, 25, 660-675. https://doi.org/10.2307/749578

Lichtman, M. (2006). Qualitative research in education: A user's guide. Thousand Oaks, CA: Sage.

Looney, L., Perry, D., \& Steck, A. (2017). Turning negatives into positives: Role of an instructional math course on preservice teachers' math beliefs. Education, 138(1), 27-40.

Muis, K. R. (2008). Epistemic profiles and self-regulated learning: Examining relations in the context of mathematics problem solving. Contemporary Educational Psychology, 33(2), 177-208, https://doi.org/10.1016/j.cedpsych.2006.10.012

National Governors Association Center for Best Practices, Council of Chief State School Officers (2010). Common Core State Standards. National Governors Association Center for Best Practices, Council of Chief State School Officers, Washington D.C.

O'Shea, J., \& Leavy, A. M. (2013). Teaching mathematical problem solving from an emergent constructivist perspective: The experiences or Irish primary teachers. Journal of Mathematics Teacher Education, 16, 293-318. https://doi.org/10.1007/s10857-013-9235-6

Pintrich, P. R. (2002). The role of metacognitive knowledge in learning, teaching, and assessment. Theory into Practice, 41(4), 219-225. https://doi.org/10.1207/s15430421tip4104_3

Polani, M. (1958). Personal knowledge. Chicago, IL: The University of Chicago Press.

Rockoff, J. E., \& Speroni, C. (2010). Subjective and objective evaluations of teacher effectiveness. American Economic Review, 100(2), 261-66. https://doi.org/10.1257/aer.100.2.261

Sadala, M. L., \& Adorno, R. F. (2002). Phenomenology as a method to investigate the experience lived: A perspective from Husserl and Merleau Ponty's thought. Journal of Advanced Nursing, 37(3), 282-293. https://doi.org/10.1046/j.1365-2648.2002.02071.x

Sanger, M. N., \& Osguthorpe, R. D. (2011). Teacher education, preservice teacher beliefs, and the moral work of teaching. Teaching and Teacher Education, 27(3), 569-578. https://doi.org/10.1016/j.tate.2010.10.011

Scheffler, I. (1968). The concept of teaching. In C.J.B. Macmillan and T.W. Nelson (Eds.), Concepts of Teaching. Chicago: IL. Rand McNally.

Schoenfeld, A. H. (1983). Beyond the purely cognitive. Cognitive Science, 7, 329-363. https://doi.org/10.1207/s15516709cog0704_3

Schommer, M. (1994). Synthesizing epistemological belief of research: tentative understandings and provocative confusions. Educational Psychology Review, https://doi.org/10.1007/BF02213418

Schommer-Aikins, M., \& Easter, M. (2006). Ways of knowing and epistemological beliefs: Combined effect on academic performance. Educational Psychology, 26, 411-423. https://doi.org/10.1080/01443410500341304

Schraw, G., \& Sinatra, G.M. (2004). Epistemological development and its impact on cognition in academic $\begin{array}{lllll}\text { domains. } & \text { Contemporary } & \text { Educational }\end{array}$ https://doi.org/10.1016/j.cedpsych.2004.01.005

Schulte, A. (2013) Personal epistemology and teacher education. Teaching Education, 24(1), 112-114. https://doi.org/10.1080/10476210.2012.727315

Torrey, T. (2017). Motivation, empowerment, and innovation: Teachers' beliefs about how participating in the Edmodo Math Subject Community shapes teaching and learning. Journal of Research on Technology in Education, 49(2), 16-30.

van Kaam, A. (1966). Existential foundations of psychology. Pittsburgh, PA: Duquesne University Press.

van Manen, M. (2003). Phenomenology online. Retrieved from http://www.phenomenologyonline.com/websites/ websites.html

Wenglinsky, H. (2000). How Teaching Matters: Bringing the Classroom Back into Discussions of Teacher Quality. ETS Policy Information Center Report. Retrieved from https://www.ets.org/research/policy_ research_reports/publications/report/2000/idxn

Yadav, A., Herron, M., \& Samarapungavan, A. (2011). Epistemological Beliefs in Preservice Teacher Education. In J. Brownlee, G. Schraw, \& D. Berthelsen (Eds.), Personal Epistemology and Teacher Education (pp. 24-39). New York, NY: Routledge.

http://www.iejme.com 